\title{
Cogwheel loading as a moving test load for bridges - analysis and laboratory experiments
}

\author{
Jan Bayer ${ }^{1 *}$, Shota Urushadze ${ }^{1}$, Jong-Dar Yau $^{2}$ and Yeong-Bin Yang ${ }^{3}$ \\ ${ }^{1}$ ITAM CAS, Prosecká 76, 19000 Praha 9, Czech Republic \\ ${ }^{2}$ Department of Architecture, Tamkang University, New Taipei City, Taiwan 25137 \\ ${ }^{3}$ School of Civil Engineering, Chongqing University, Chongqing, 400044 China
}

\begin{abstract}
A moving impulse load generated by a heavy cogwheel can be used as a testing excitation for bridges. This novel type of dynamic load acts along the entire driving path, its intensity is adjustable, and it can be very efficient in the case of resonance. Verification tests were performed on a model under laboratory conditions and compared to numerical simulation. The results are extensively discussed.
\end{abstract}

\section{Introduction}

Bridge load testing is as old as the first bridges, and ways of testing them have been systematically evolving for more than a hundred years [1-3]. The dynamic properties of bridges are tested using either usual traffic [1,4], ambient vibrations [1,5], dynamic shakers $[1,6]$, rockets [7,8], dropping weights [1], the passing of heavy vehicles [7] or vehicles passing across an obstacle [7-10], and recently, drive-by testing [11,12]. Each type of loading has its advantages and inconveniences and therefore also typical fields of application [13].

Traffic is not a well-defined load (it is more suitable for continuous monitoring); dynamic shakers provide local loading that is not always capable of exciting global behaviour especially in large structures; impulse loading from rockets or dropping weights is of short duration; the load from an obstacle is short and localized; and the loading from passing heavy vehicles and drive-by identification has to account for the changing surface of the road, not to mention other phenomena, e.g. nonlinearities of various kinds. This list of possible problems is far from complete, and a detailed comparison of the efficiency of the abovementioned methods would require extensive research which is not the aim of this article.

Moving dynamic loads, besides in the already mentioned drive-by identification, have been studied for a long time [14] with some recent interesting applications [15,16]. The proposed test load - a passing cogwheel - may find its specific field of applications, and this article presents the first comparison of analytical approaches and experimental results on a laboratory model.

The Idea of the passing cogwheel comes from repeating the obstacle test [7-10] along the entire driving path across the bridge which circumvents the problems related to local excitation. It also offers the possibility of exciting large structures, providing an alternative to ambient vibrations testing [3].

*Corresponding author: bayer@itam.cas.cz 
Using a standard obstacle (a plank) for the evaluation of dynamic increment has been a common practice in the Czech Republic for a long time [10]. The dynamic increment while testing with the obstacle is regularly higher than without it [7] and would have approximately the same effect as a single impulse from a hexa- or heptagonal wheel of a truck. Thus the intensity of the cogwheel load is expected to overcome the effects of the sprung mass applied during the drive-by test with the same mass.

The final goal is an attempt to apply the cheap and efficient cogwheel load to damage diagnosis of bridges.

\section{The cogwheel load}

The revolving cogwheel causes a moving impulse excitation whose intensity is related to on the number of edges, the mass and the speed of the cogwheel, and the mechanical properties of its tips. However, determining the loading function is not an elementary task. It is possible to derive the maximum vertical acceleration (1) of the cogwheel's centre of gravity just before the tip reaches the surface (see the diagram in Figure 1). But at the moment of contact there is singularity of the theoretical (from the Figure 1!) movement trajectory (the real trajectory includes the deformation of the tips), and therefore the impulse force derived from the acceleration (1) may not be a precise estimation.

$$
a_{\mathrm{y}, \max }=-v_{h}^{2} / r / \cos ^{3}(\pi / n),
$$

where $v_{h}$ is the horizontal velocity of the cogwheel which is assumed to be constant, $r$ is the radius of the cogwheel, and $n$ is the number of its edges (teeth).

Another possibility is to start with the impulse derived from the maximum vertical velocity (2)

$$
v_{\mathrm{y}, \max }=-v_{h} \cdot \tan (\pi / n) .
$$

In this case, it is also necessary to guess or estimate the shape of the force function in order to derive a peak force from the time integral of the function equal to the impulse $\left(v_{h} \bullet\right.$ mass $)$. The third possibility is to rely, at least partly, on experimental investigation which is considered the best option at this stage of the project.

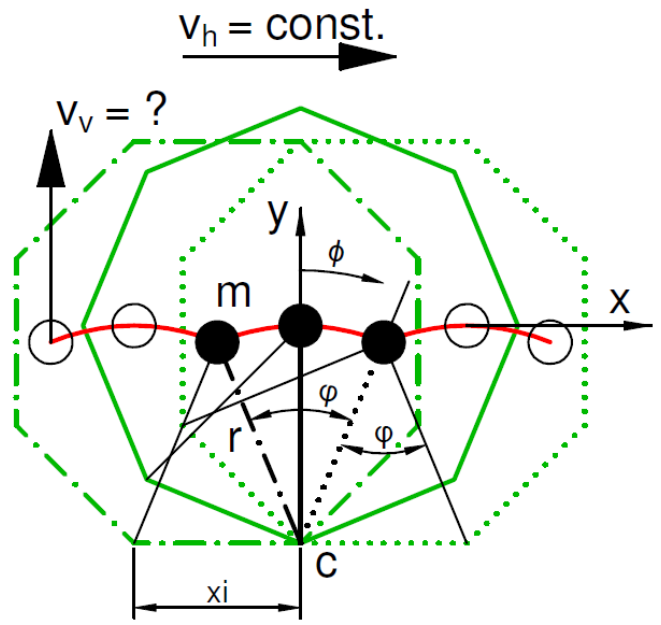

Fig. 1. Digram of the cogwheel movement. 


\section{Numerical simulation}

The problem can essentially be analysed either as a moving mass \& force or as a moving force. As the moving mass changes the mass distribution of the structure during passage, it consequently changes the dynamic properties of the system (the natural frequencies and mode shapes), which can theoretically cause non-linear phenomena in the response of the structure. A moving force does not exhibit this effect. As this phenomenon may have an effect on the vibration response, both approaches were studied using ANSYS. For the experimental site described below, the relation of the moving mass to the bridge mass $\mathrm{m}_{\mathrm{v}} / \mathrm{m}_{\mathrm{b}}$ was about $1,5 \%$. In this case, the first natural frequency of the beam and moving mass system also changes by about $1,5 \%$ when the mass changes its position along the beam. Let us consider the moving force first. A closed form solution exists [17], and it is also quite easy to apply as a general time dependent load within the framework of the transient analysis in ANSYS.

The closed form solution for a moving mass on a beam has been around since 1985 [18], but for practical reasons it was not included in this study. ANSYS offers a solution with contact elements (it theoretically allows for lower model resolution) or the continuous changing of material properties (MPCHG - density option) within the framework of the transient analysis. The latter approach seems to be less demanding and more reliable than the first, based on the authors' experience.

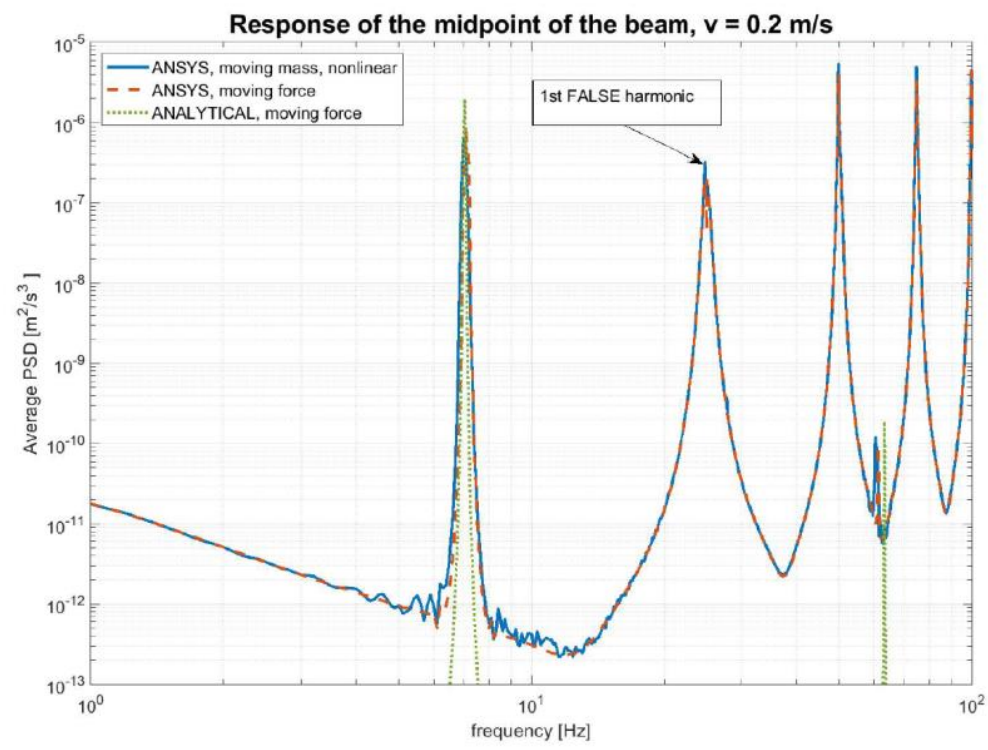

Fig. 2. Comparison of averaged PSD for analytical and finite element solutions.

The finite element solution has the disadvantage that it generates false frequency peaks due to the space resolution of the model. Therefore, the element size $s_{\mathrm{e}}$ should be smaller than $v_{h} / f_{i}$, where $f_{i}$ is the highest frequency of interest in $\mathrm{Hz}$, which in general requires a quite dense element network. This, together with the numerical integration applied within the transient analysis done in ANSYS, leads to long solution times.

An illustration of the above-mentioned issues is given in Figures 2 and 3. The finite element model used had 500 nodes on the driving path (with an element side of $8 \mathrm{~mm}$ and a total of 8574 shell elements) which, for the driving velocity $v_{h}=0.2 \mathrm{~m} / \mathrm{s}$ allowed for an applicable frequency band of only up to $f_{i}=25 \mathrm{~Hz}$. The influence of the changing mass during the passage of the vehicle is negligible as shown by the comparison of averaged power spectral 
densities (PSD) in Figure 2. The finite element analysis in the time domain should be interpreted cautiously because the time response without any, or with an unsuitable, low-pass filter may be substantially biased, as comparing the analytical solution with application of a $100 \mathrm{~Hz}$ low-pass filter to the finite element results shows in Figure 3. If we wanted to use the results of ANSYS' transient analysis in a range up to $100 \mathrm{~Hz}$, it would require a resolution of 4000 elements along the length of the beam (making a total of over 100000 elements) which would require an incredibly long solving time for a simple supported beam problem.

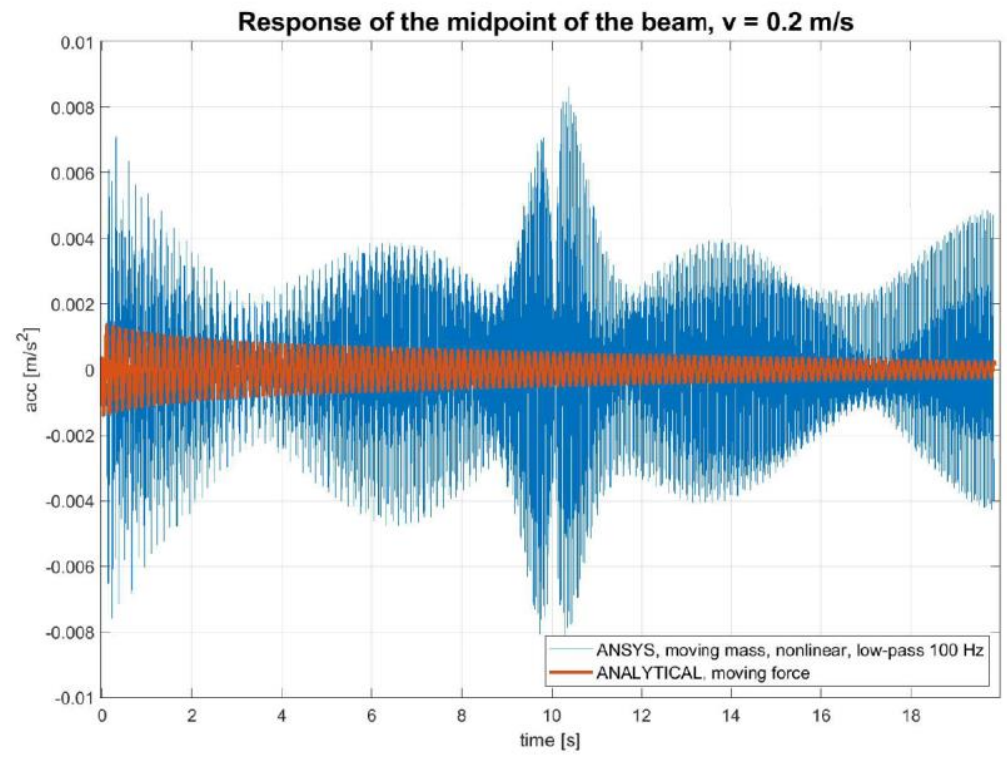

Fig. 3. Comparison of analytical and finite element solution in the time domain.

The solution time can be reduced by using only the few first vibration modes, but for each position of the moving mass, which is not offered by ANSYS and has to be solved e.g. with MATLAB using the modal parameters obtained from a FEM software.

\section{Experiments}

The 4m-long simply-supported model was made from Jäckel steel U-210x50x4 mm and has a mass of $33.3 \mathrm{~kg}$. The measured and analytical natural frequencies of the model are presented in Table 1.

Table 1. Comparison of computed and measured natural frequencies.

\begin{tabular}{|c|c|c|c|}
\hline Mode No. & $\begin{array}{c}\text { Analytical frequencies } \\
{[\mathrm{Hz}]}\end{array}$ & $\begin{array}{c}\text { Experimental frequencies } \\
{[\mathrm{Hz}]}\end{array}$ & $\begin{array}{c}\text { Estimated damping ratio } \\
{[\%]}\end{array}$ \\
\hline 1 & 6.98 & 7.01 & 0.12 \\
\hline 2 & 13.41 & 11.84 & 0.3 \\
\hline 3 & 27.74 & 27.66 & 0.23 \\
\hline 4 & 36.10 & 34.78 & 0.3 \\
\hline 6 & 60.89 & 59.94 & 0.6 \\
\hline
\end{tabular}


A high speed camera confirmed that the cogwheel reaches an impact acceleration of over one g already at slow velocities which causes "jumping" as a consequence. Therefore, only two relatively low vehicle speeds of 0.1 and $0.2 \mathrm{~m} / \mathrm{s}$ were considered. Tests were performed with a moving mass of $0.502 \mathrm{~kg}$ in the form of a cogwheel with 6,7,8 and 10 edges.

The average power spectral density (PSD) from the midpoint of the beam is plotted in Figure 4. A considerable influence of higher harmonic components is obvious from the figure. Similar results could be obtained using a cogwheel with a constant number of edges but with varying passing velocities. Repeatedly adjusting the velocity by small increments makes it possible to localize the frequency peaks accurately (see fig. 5).

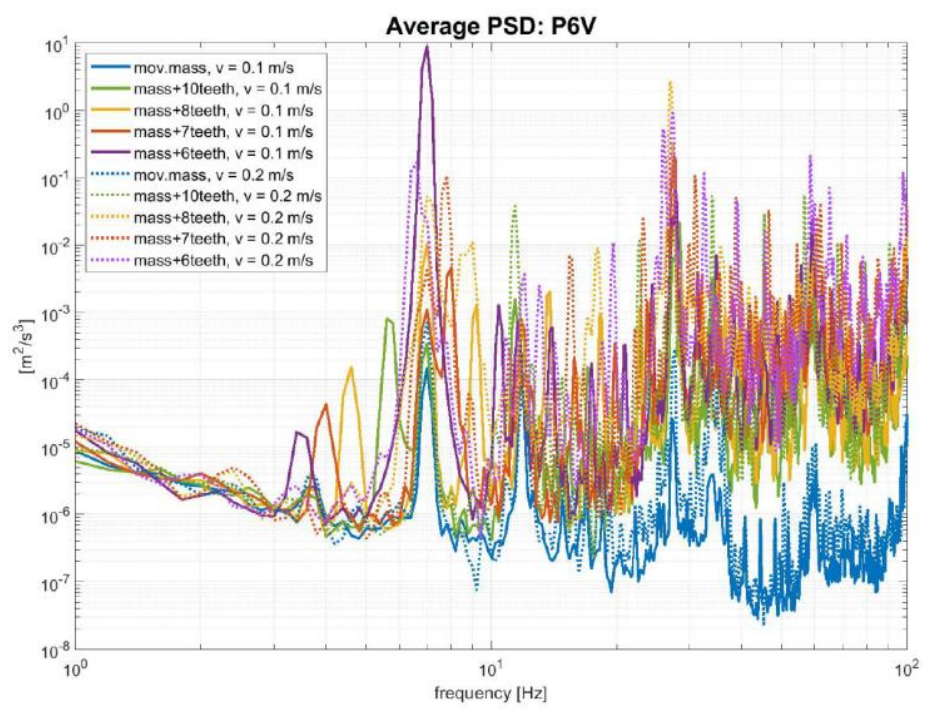

Fig. 4. Measured average PSD at the right side at the location 5/8L on the U-beam.

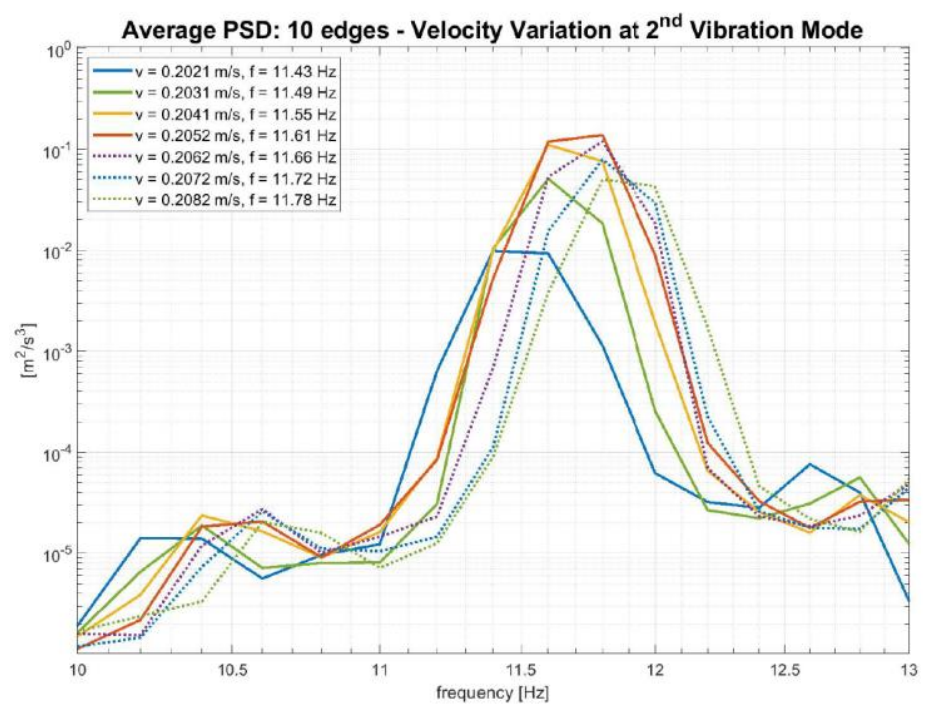

Fig. 5. Measured average PSD at the same location as above during velocity variation. 


\section{Conclusions}

The above described cogwheel load can theoretically be used to test bridges. It is not likely to became a general tool for bridge testing, but thanks to the following advantages it may find a specific application field in future:

$\checkmark$ cost effective,

$\checkmark$ efficient and precise in exciting the vertical vibration modes,

$\checkmark$ acting along the whole driving path (not dependent on excitation points),

$\checkmark$ not sensitive to surface roughness (as other drive-by techniques),

not to mention the fact that it provides a well-defined input and can theoretically be an alternative to ambient vibration tests of large structures.

As the tests are still at the very beginning, there is also a certain potential to develop appropriate measuring and evaluation procedures tailored to this type of excitation. Response analysis of bridges loaded by a dynamic load causing higher harmonic components is a demanding and challenging task, as was documented in the presented analysis.

The supports of grants GA CR 17-26353J and joint project via grant MOST 106-2923-E032-007-MY3 are gratefully acknowledged. Identification code of research project of the Institute of Theoretical and Applied mechanics is AVOZ 6838297.

\section{References}

1. A. Cunha, E. Caetano, F. Magalhães, C. Moutinho, Struct. Control Health Monit. 2013; 20(6)

2. E. O. Lantsoght, CRC Press, (2019)

3. Ch.R. Farrar, T.A. Duffey, P.J. Cornwell, S.W. Doebling IMAC XVII, Feb. 1999, Kissimmee, Florida

4. J.M.W. Brownjohn, R.T. Severn, 10th World Conference of Earthquake Engineering, (1992) Balkema, Rotterdam

5. M. Venglár, M. Sokol, R. Ároch R., Journal of Measurements in Engineering. 6, 4 (2018)

6. M. Pirner, O. Fischer, Dynamika ve stavební praxi, ČKAIT, Praha (2010)

7. J. Benčat, R. Kohár, Intech Open, Bridge Engineering, Ch.7, (Edited by Hamid Yaghoubi), 2018

8. S. Pietrzko, R. Cantieni, 14th IMAC Dearborn, Michigäh, February 1 2-15, 1996, p.9198

9. R. Cantieni, Dynamic Load Testing of Highway Bridges, IABSE Proc. 3 (1984)

10. ČSN 736209, Zatěžovací zkoušky mostů, Czech National Standard, (1996)

11. Y.B. Yang, C.W. Lin, J-D. Yau, Journal of Sound and Vibration, May (2004)

12. Y.B. Yang, C.W. Lin, Journal of Sound and Vibration 284, (2005)

13. Commander B., Front. Built Environ. 5:57

14. C.E Inglis, A Mathematical Treatise on Vibrations in Railway Bridges, Pp. xxv, 203, 21s., 1934. (Cambridge)

15. Y. Zhang, L. Wang, Z. Xiang, Journal of Sound and Vibration 331 ( 2012)

16. E.J. O’Brien, D. Martinez, A. Malekjafarian, E. Sevillano (2017) J.Civil Struct Health Monit, 7

17. Y.B. Yang, J-D. Yau, Y.S. Wu, World Scientific Publishing Co. Pte. Ltd., 2004 
18. M.M. Stanišič, Ingenieur-Archiv 55 (1985) 